\title{
PERBANDINGAN PENGOLAHAN DAS BENGKULU MENGGUNAKAN NDVI DAN MAXIMUM LIKELIHOOD
}

\author{
Asahar Johar ${ }^{1}$, Arie Vatresia ${ }^{2}$, Rendra Regen Rais $^{3}$ \\ ${ }^{1}$ Sistem Informasi, Fakultas Teknik, Universitas Bengkulu, Indonesia \\ ${ }^{2}$ Informatika, Fakultas Teknik, Universitas Bengkulu, Indonesia \\ ${ }^{3}$ BKSDA Bengkulu, Kementrian Lingkungan Hidup dan Kehutanan, Indonesia \\ ${ }^{1}$ asahar.johareunib.ac.id \\ 2arie.vatresia@unib.ac.id \\ ${ }^{3}$ r.regen.raiseprotonmail.ch
}

Abstrak: DAS adalah daerah daratan yang merupakan bagian integral dari sungai dan anak-anak sungainya. DAS berfungsi untuk menampung, menyimpan dan mengalirkan air yang berasal dari curah hujan ke danau atau ke laut secara alami, batas di darat adalah pemisah topografi dan batas di laut ke perairan yang masih dipengaruhi oleh aktivitas darat. Pemetaan tutupan lahan di daerah aliran sungai penting untuk memahami masalah yang terjadi di daerah aliran sungai seperti kualitas air yang menurun dan rentan terhadap tanah longsor atau banjir. Dalam studi ini, pemetaan area penutup DAS Rindu Hati dilakukan dari 2014 hingga 2018 dengan menggunakan citra satelit Landsat 8 menggunakan metode Maximum Likelihood dan NDVI. Peta tutupan lahan kemudian diproses dan ditampilkan menggunakan media webGIS. Penelitian ini diharapkan dapat menjadi bahan pertimbangan untuk pengambilan keputusan dalam pengelolaan DAS Rindu Hati di masa depan untuk mendukung lingkungan yang berkelanjutan. Selain itu, penelitian ini menunjukkan bahwa kinerja algoritme kemungkinan maksimum menghasilkan akurasi yang lebih baik $(95,81 \%)$ daripada hasil yang dihasilkan oleh NDVI $(92,85 \%)$ untuk proses klasifikasi di DAS Rindu Hati. Pengujian dilakukan ke dalam 100 titik data acak dari hasil klasifikasi dalam kegiatan pemeriksaan lapangan. Kemungkinan maksimum juga menunjukkan waktu pemrosesan yang lebih baik untuk klasifikasi 5 kelas pada nilai rata-rata 0,023 detik daripada algoritme NDVI yang menunjukkan nilai rata-rata 0,031 detik.

Kata Kunci: DAS, maximum likelihood, NDVI, remote sensing, webGIS.

Abstract: A watershed (DAS) is a land area which is an integral part of a river and its tributaries. The watershed functions to accommodate, store and flow water that comes from rainfall to lakes or to the sea naturally, the boundary on land is a topographic separator and the boundary in the sea to waters that are still affected by land activities. Mapping land cover in the watershed area is important to understand the problems that occur in the watershed area such as declining water quality and prone to landslides or floods. In this study, a mapping of Rindu Hati Sub-watershed land cover area was carried out from 2014 to 2018 by utilizing Landsat 8 satellite imagery using the Maximum Likelihood and NDVI method. The land cover map is then processed and displayed using webGIS media. This research is expected to be a material consideration for decisions in the management of
Rindu Hati Watershed in the future to support a sustainable environment. Additionally, this research shown that the performance of maximum likelihood algorithm produced a better accuracy (95.81\%) than the result produce by NDVI (92.85\%) for the process of classification in Rindu Hati Watershed. The testing was performed into 100 random data points of the classification result in the ground check activity. Maximum likelihood also showing a better time processing for 5 classes classification in the average value of $0.023 \mathrm{~s}$ than the NDVI algorithm that showed the average value of 0.031 s.

Keywords: DAS, maximum likelihood, NDVI, remote sensing, webGIS 
Jurnal Pseudocode, Volume VII Nomor 2, September 2020, ISSN 2355-5920, e-ISSN 2655-1845 www.ejournal.unib.ac.id/index.php/pseudocode

\section{PENDAHULUAN}

DAS adalah wilayah daratan yang merupakan bagian integral dari sungai dan anak-anak sungainya, yang berfungsi untuk menampung, menyimpan, dan mengalirkan air yang berasal dari curah hujan ke danau atau ke laut secara alami, batas daratan adalah pemisah topografi dan batasbatas dalam laut ke perairan yang masih dipengaruhi oleh aktivitas darat [1], [2]. Pengelolaan daerah aliran sungai didefinisikan sebagai upaya manusia dalam mengatur keterkaitan antara sumber daya alam dan manusia di daerah aliran sungai dan semua kegiatannya, sehingga keberlanjutan dan keharmonisan ekosistem dan realisasi penggunaan ekosistem secara berkelanjutan bagi manusia akan terwujud [3]. Namun, [4] menyatakan bahwa pengelolaan DAS pada prinsipnya adalah pengaturan penggunaan lahan atau optimalisasi penggunaan lahan untuk berbagai keperluan secara rasional dan praktik ramah lingkungan lainnya sehingga dapat dinilai dengan indikator kunci (indikator utama) kuantitas, kualitas dan kontinuitas aliran sungai di outlet DAS. Berdasarkan hal ini, itu berarti bahwa faktor penggunaan lahan memiliki peran penting dalam pengelolaan daerah aliran sungai.

DAS Air Bengkulu [5] meliputi wilayah seluas 51.500 ha dan terletak di dua kabupaten / kota di Bengkulu (Kota Bengkulu Tengah dan Kota Bengkulu). Sungai utama di DAS ini adalah Sungai Air Bengkulu. DAS ini dibagi menjadi 3 DAS, yaitu DAS Rindu Hati, DAS Susup, dan DAS Bengkulu Hilir. Enam anak sungai yang mengalir ke Sungai Air Bengkulu adalah Sungai Susup, Sungai Rindu Hati, Sungai Kemumu, Sungai Pasemah, Sungai Sialang dan Sungai Muara Kurung. Sungai Susup adalah bagian dari Sub DAS Susup. Sungai Rindu Hati dan Kemumu membentuk Sub DAS Rindu Hati. Sungai Pasemah, Sialang, dan Muara Kurung membentuk Sub DAS Bengkulu Hilir.

Sejauh ini, belum ada peta spesifik yang menjelaskan tutupan lahan di wilayah DAS Air Bengkulu, khususnya wilayah DAS Rindu Hati. Peta tutupan lahan di daerah aliran sungai penting untuk memahami permasalahan yang terjadi di perairan Bengkulu seperti menurunnya kualitas air bersih atau rawan longsor atau banjir. Menurut [6], [7], perubahan dalam penggunaan lahan dan praktik pengelolaan daerah aliran sungai mempengaruhi erosi, sedimentasi dan pada gilirannya mempengaruhi kualitas air. Pemodelan adalah salah satu cara untuk mempelajari objek atau fenomena dunia nyata (dunia nyata). Model ini pada dasarnya adalah penyederhanaan atau bentuk sederhana dari objek dunia nyata. Kompleksitas fenomena dunia nyata adalah hambatan utama yang dihadapi peneliti untuk memeriksanya secara langsung. Melalui pemodelan, fenomena kompleks disederhanakan untuk membuatnya lebih mudah dipelajari tanpa kehilangan substansi [8]. Pemodelan area tutupan lahan dapat dilakukan dengan memanfaatkan penginderaan jauh dan sistem informasi geografis, yaitu penggunaan citra satelit dalam penelitian ini dalam bentuk Landsat 8 . Hasil penelitian ini dapat dipertimbangkan dalam menentukan kebijakan pemerintah daerah dalam membuat peraturan daerah tentang tutupan lahan di wilayah Daerah Aliran Sungai (DAS).

\section{METODOLOGI}

Wilayah studi dari penelitian ini adalah Sub DAS Rindu Hati. Daerah ini terletak di pusat kabupaten Bengkulu, Kabupaten DAS Rindu Hati, yang mencakup beberapa desa, termasuk Desa 
Jurnal Pseudocode, Volume VII Nomor 2, September 2020, ISSN 2355-5920, e-ISSN 2655-1845 www.ejournal.unib.ac.id/index.php/pseudocode

Karang Tengah, Kota Niur, Detak Jantung, DAS Rindu Hati, Taba Teret, Tanjung Heran dan Tanjung Raman. Batas-batas Sub DAS Detak Jantung dapat dilihat pada Gambar berikut.

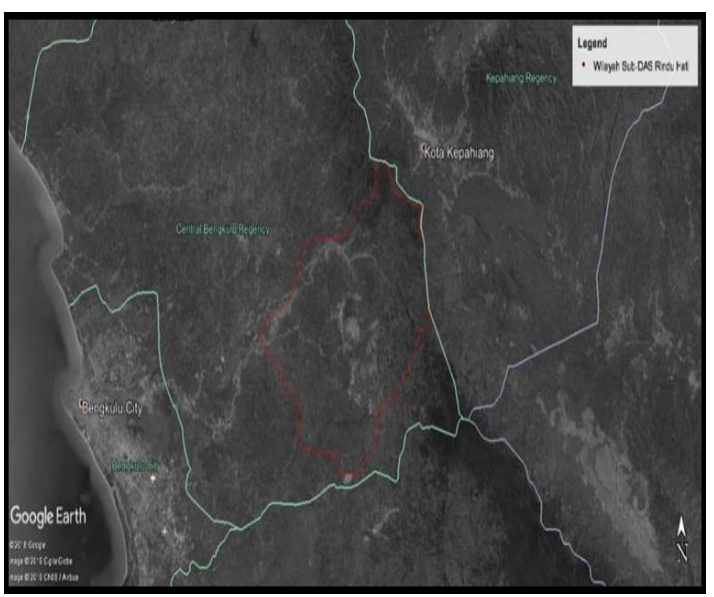

Gambar 1 Lokasi Rindu Hati

Penelitian ini akan menggunakan data penginderaan jauh, yaitu data Landsat 8 Image yang diunduh di situs resmi Landsat 8, yaitu https://earthexplorer.usgs.gov yang berguna untuk analisis data titik-titik hutan yang terkena dampak deforestasi menggunakan Metode Normalisasi Perbedaan dalam Vegetasi atau Indeks NDVI (Indeks Perbedaan Beda Normalisasi) [9], [10] dan proses Kemungkinan Maksimum. Penjelasan rinci pada Gambar 1 untuk diagram alur pekerjaan penelitian sebagai berikut:

1. Menggunakan gambar mentah dari gambar Landsat 8 dari 2013 - 2018.

2. Proses penggabungan (komposit) di band 6.5 dan 4 landsat 8 menggunakan Er-Mapper.

3. Lakukan proses Koreksi Geometrik dan lakukan proses penentuan titik-titik GCP pada pita-pita dari 6 citra Landsat 8, serta melakukan proses Koreksi Radiometrik.
4. Potong gambar sesuai dengan studi kasus penelitian, yaitu kawasan hutan DAS Rindu Hati.

5. Melakukan proses NDVI dan Maximum Likelihood [11] yang ada di ArcMap Software.

6. Setelah melakukan proses NDVI dan Kemungkinan Maksimum, lanjutkan dengan proses klasifikasi ulang.

7. Membuat Model Peta Tematik untuk kondisi hutan di daerah DAS Rindu Hati.

8. Lakukan proses overlay.

9. Analisis data dilakukan dari proses reklasifikasi.

10. Dokumentasi ke dalam sistem WebGIS.

\section{A. Metode Pengumpulan Data}

Metode ini dilakukan dengan mengumpulkan data yang diperoleh dari berbagai literatur, seperti buku dan media internet yang terkait dengan penelitian, yang membahas Model Pemetaan, Klasifikasi Kemungkinan Maksimum, dan Desain WebGIS [12], [13] sehingga dapat membantu proses melakukan tugas akhir.

Data yang diperlukan untuk melakukan penelitian ini meliputi:

a. Landsat 8 pada tahun 2018, 2017, 2016, 2015 dan 2014

b. Peta Pemerintahan Kabupaten Bengkulu Tengah

c. Peta situs Air Bengkulu

d. Beberapa literatur yang digunakan sebagai referensi dalam penelitian ini meliputi:

e. Identifikasi Karakteristik dan Pemetaan Penutupan Lahan Menggunakan Citra Landsat 8 (Minyak) di Kabupaten Pesawaran, Provinsi Lampung 
Jurnal Pseudocode, Volume VII Nomor 2, September 2020, ISSN 2355-5920, e-ISSN 2655-1845 www.ejournal.unib.ac.id/index.php/pseudocode

f. Penilaian Algoritme Indeks Vegetasi dan mengklasifikasikan kelas tutupan lahan Metode Klasifikasi dari Data Satelit Landsat-5 berdasarkan rona dan pola yang ditampilkan pada Tm dan Landsat-7 Etm +

g. Studi Model Pengelolaan Wilayah Sungai Terpadu

h. Sistem Informasi Geografis: Prinsip Dasar dan Pengembangan Aplikasi

Metode studi analitik ini dilakukan dengan menganalisis warna dan pola pada citra satelit Landsat 8 kemudian dibandingkan dengan keadaan tutupan lahan di lapangan dengan menggunakan aplikasi Google Earth Pro.

\section{B. Metode Pengembangan Sistem}

Input data atau input yang dibutuhkan dalam sistem ini adalah data dari interpretasi gambar visual yang merupakan data primer, dan data sekunder berupa gambar peta digital dari satelit Landsat 8 dengan spesifikasi tutupan awan di bawah $30 \%$ dan peta bentuk air Sungai Bengkulu.

Data keluaran dalam sistem ini adalah model pemetaan yang menampilkan informasi dalam bentuk dan jenis tutupan lahan di daerah DAS Rindu Hati pada tahun 2018 serta grafik area tutupan lahan.

Antarmuka pada aplikasi adalah kemudahan dan kenyamanan pengguna saat mengakses aplikasi sesuai dengan masalah yang ada.

Berikutnya adalah fase desain atau desain sistem. Tahap ini adalah proses multi-langkah yang berfokus pada desain pemrograman perangkat lunak. Pada tahap ini, langkah-langkah yang diambil adalah menentukan aliran program menggunakan Data Flow Diagram (DFD), aliran desain antarmuka, dan pemrosesan gambar. Pada tahap pemrosesan gambar, sejumlah proses dilakukan untuk menyiapkan gambar sehingga siap untuk diproses menjadi tutupan lahan dengan gambar.

Pada tahap implementasi, penulis mengimplementasikan hasil desain yang dibuat pada tahap desain. Proses yang akan dilakukan pada tahap ini adalah pengkodean sistem. Proses yang akan dilakukan pada tahap ini adalah membuat sistem berbasis web menggunakan bahasa pemrograman php dan javascript untuk menampilkan hasil yang diperoleh dari tahap pemrosesan gambar, yaitu model penutupan lahan.

Tahapan pemeliharaan (maintenance) dilakukan sebelum sistem informasi telah dioperasikan. Sebelum sistem dioperasikan, uji fungsional dan teknis dilakukan pada sistem yang dibangun menggunakan metode Black Box, apakah sudah sesuai dengan tujuan penelitian ini, yaitu apakah sistem dibangun dengan benar dan benar sehingga dapat tampilkan informasi tentang tutupan lahan DAS di daerah DAS Rindu Heart melalui media WebGIS.

\section{HASIL}

Proses ini menggunakan metode perhitungan faktor indeks optimal (OIF). Perhitungan OIF ini bertujuan untuk memilih kombinasi pita terbaik untuk mengetahui gambar awal dalam mengidentifikasi pola distribusi tutupan lahan. Dari citra Landsat pada Mei 2018, data diperlukan untuk melakukan perhitungan OIF, yaitu nilai standar deviasi dan matriks korelasi seperti yang ditunjukkan pada tabel berikut. 
Jurnal Pseudocode, Volume VII Nomor 2, September 2020, ISSN 2355-5920, e-ISSN 2655-1845 www.ejournal.unib.ac.id/index.php/pseudocode

\begin{tabular}{|c|c|c|c|c|c|c|c|}
\hline \multirow{2}{*}{ Corr } & \multicolumn{7}{|c|}{ Band } \\
\hline & 1 & 2 & 3 & 4 & 5 & 6 & 7 \\
\hline Band 1 & 1 & 0,96 & 0,95 & 0,88 & 0,18 & 0,71 & 0,84 \\
\hline Band 2 & 0,96 & 1 & 0,98 & 0,92 & 0,18 & 0,71 & 0,82 \\
\hline Band 3 & 0,95 & 0,98 & 1 & 0,93 & 0,21 & 0,74 & 0,83 \\
\hline Band 4 & 0,88 & 0,92 & 0,93 & 1 & 0,13 & 0,72 & 0,79 \\
\hline Band 5 & 0,18 & 0,18 & 0,21 & 0,13 & 1 & 0,45 & 0,2 \\
\hline Band 6 & 0,71 & 0,71 & 0,74 & 0,72 & 0,45 & 1 & 0,85 \\
\hline Band 7 & 0,84 & 0,82 & 0,83 & 0,79 & 0,2 & 0,85 & 1 \\
\hline Stdev & 1816,02 & 1894,02 & 1928,82 & 2030,02 & 2673,16 & 2091,88 & 1821,34 \\
\hline
\end{tabular}

Dengan data seperti tabel di atas dan dihitung menggunakan Persamaan (2.1), Anda bisa mendapatkan hasil perhitungan faktor indeks optimal dari citra Landsat pada Mei 2018. Berdasarkan hasil perhitungan OIF [14], [15] pada Lampiran 7, kombinasi pita 7, pita 5 dan band 4 memiliki nilai OIF tertinggi. Berdasarkan nilainilai ini, kombinasi band 7-5-4 dipilih sebagai kombinasi band yang digunakan dalam penelitian ini karena penampilan visual gambar lebih dekat dengan warna alami. Perbandingan penampilan kombinasi dapat dilihat pada Gambar di bawah ini.

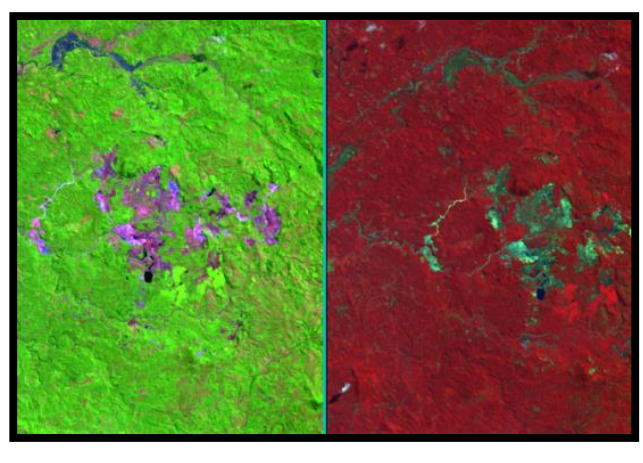

Gambar 2. Komposit Citra

Hasil Klasifikasi Citra Landsat 8 di Kawasan Hutan Kabupaten DAS Rindu Hati pada Gambar 2. Hasil analisis menunjukkan sejauh mana setiap klasifikasi dan mencari tahu tutupan lahan dari masing-masing klasifikasi. Data menunjukkan bahwa pada tahun 2013, Klasifikasi Vegetasi Sangat Padat mendominasi dengan luas 35\% 8,322
Ha, 2014 didominasi oleh klasifikasi Vegetasi Padat dengan persentase $37 \%$ dengan luas 8,903 Ha, pada tahun 2015 didominasi oleh klasifikasi Vegetasi Padat dengan persentase $38 \%$ dengan luas 9.092 Ha dari total luas $23.746 \mathrm{Ha}$, pada tahun 2016 didominasi oleh klasifikasi Vegetasi Sangat Padat dengan persentase $33 \%$ dengan luas 7.800 Ha, 2017 didominasi oleh klasifikasi Vegetasi Padat dengan persentase $37 \%$ dengan luas 8.754 Ha, pada tahun 2018 didominasi oleh klasifikasi Vegetasi Sangat Padat dengan persentase $42 \%$ dengan luas $10.042 \mathrm{Ha}$.

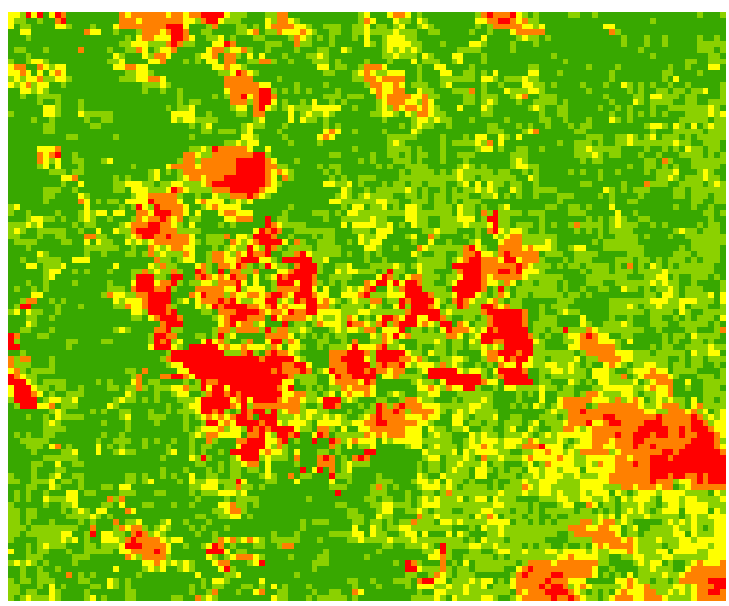

(a) 
Jurnal Pseudocode, Volume VII Nomor 2, September 2020, ISSN 2355-5920, e-ISSN 2655-1845 www.ejournal.unib.ac.id/index.php/pseudocode

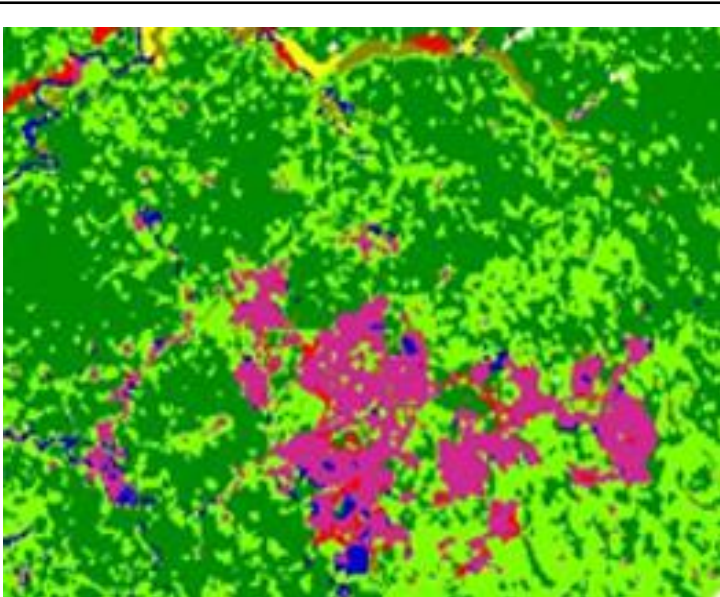

(b)

Gambar 3. (a) Hasil Klasifikasi NDVI pada DAS (b) Hasil Klasifikasi maximum likelihood pada DAS

Proses pemeriksaan lapangan berguna untuk menentukan tingkat keberhasilan metode NDVI. Pemeriksaan lapangan juga bermanfaat sebagai batasan dalam menghitung luas hutan dan nonhutan. Berikut ini adalah hasil pemeriksaan lapangan di wilayah Kecamatan DAS Rindu Hati pada Tabel 1.

Tabel 2. Hasil Pengecekan Lapangan

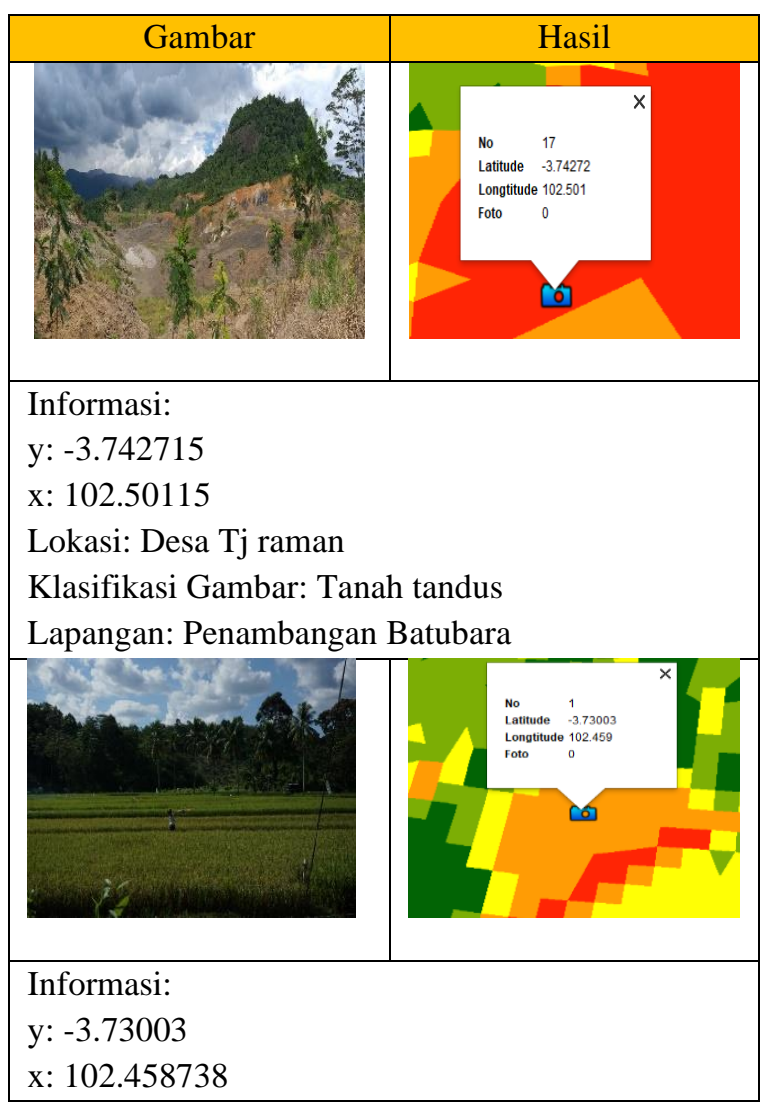

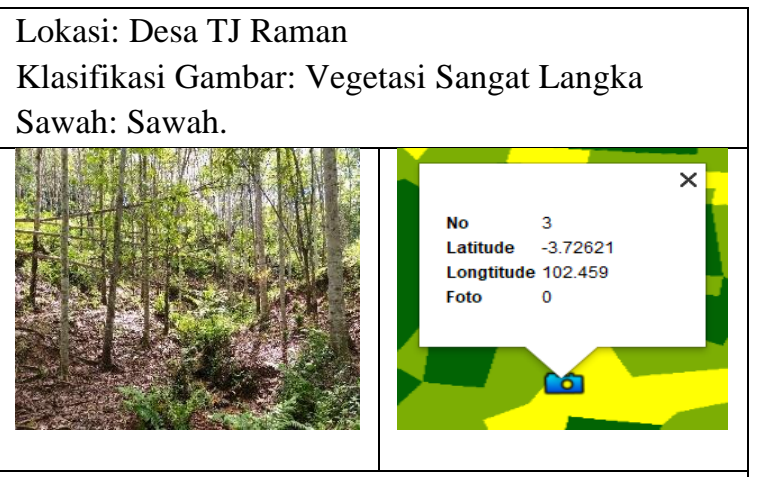

Informasi:

$y:-3.726213$

$\mathrm{x}: 102.458926$

Lokasi: Desa TJ Raman

Klasifikasi Gambar: Vegetasi Jarang

Lapangan: Pohon karet
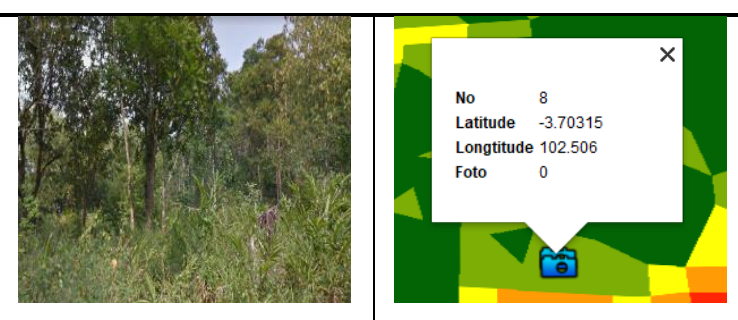

Informasi:

y: -3.703153

$\mathrm{x}: 102.505679$

Lokasi: Desa Lubuk Sini

Klasifikasi Gambar: Vegetasi Padat

Lapangan: Pohon, Semak dan Tanaman Bambu.

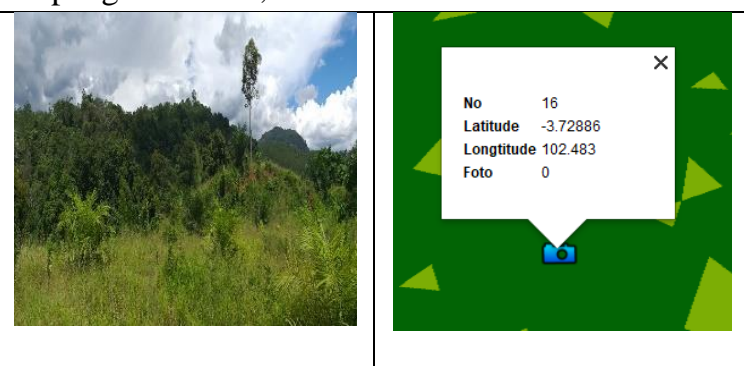

Informasi:

y: -3.72886

$\mathrm{x}: 102.482878$

Lokasi: Desa TJ Raman

Klasifikasi Gambar: Vegetasi Sangat Padat

Bidang: pohon / hutan.

Pengetesan ini [16], [17] diperlukan untuk menentukan keakuratan sistem yang sedang dirancang. Berikut ini akan dibahas tentang 
Jurnal Pseudocode, Volume VII Nomor 2, September 2020, ISSN 2355-5920, e-ISSN 2655-1845 www.ejournal.unib.ac.id/index.php/pseudocode

pengujian sistem model pemetaan area tutupan lahan berbasis webGIS yang telah dirancang sebelumnya. Pengujian black box dilakukan untuk menguji apakah sistem yang dikembangkan sesuai dengan apa yang dinyatakan dalam spesifikasi fungsional sistem. Black Box juga digunakan untuk menguji fungsi-fungsi khusus dari sistem yang dirancang. Kebenaran dari sistem yang diuji hanya dilihat berdasarkan output yang dihasilkan dari data atau kondisi input yang diberikan untuk fungsi yang ada tanpa melihat bagaimana proses untuk mendapatkan output.

Ada 100 skenario pengujian kotak hitam. Dan semua skenario memiliki realisasi yang diharapkan. Dari 20 skenario yang dilakukan selama proses penelitian, semua skenario berhasil dilakukan. Dengan ini kita dapat mengukur tingkat pengujian fungsional sistem sebagai berikut.

Kesuksesan fungsional $=x 100 \%=100 \%$.

Dengan demikian, uji kelayakan fungsional sistem mendapatkan hasil uji $100 \%$.

Metode pengujian keakuratan tutupan lahan dalam penelitian ini adalah dengan melakukan pemeriksaan tanah dan interpretasi gambar digital di titik-titik yang tersebar di wilayah studi untuk mengukur akurasi hasil model pemetaan tutupan lahan dengan tutupan lahan yang ada di lapangan. . Dari uji 98 tes yang tersebar diambil melalui interpretasi gambar digital menggunakan aplikasi Google Earth Pro dan pemeriksaan lapangan di lapangan hanya ada 94 identifikasi yang akurat atau sesuai dengan tutupan lahan yang ada di lapangan.

Dari 4 data uji yang tidak akurat, 3 di antaranya salah klasifikasi antara lahan hutan dan lahan perkebunan, sementara yang lain diindikasikan karena objek tutupan lahan terlalu kecil sehingga tidak dapat diklasifikasi dengan baik menggunakan citra Landsat 8 yang memiliki resolusi 30x30 m sebagai citra. Sedangkan dalam Hasil NDVI, hanya ada 92 identifikasi yang akurat atau sesuai dengan tutupan lahan yang ada di lapangan. Dari 8 data uji yang tidak akurat, 5 di antaranya salah klasifikasi antara lahan hutan dan lahan perkebunan, sementara yang lain diindikasikan karena objek tutupan lahan terlalu kecil sehingga tidak dapat diklasifikasi dengan baik menggunakan citra Landsat 8 yang memiliki resolusi 30x30 m sebagai citra.

Adapun dalam pengecekan waktu pemrosean data dengan menggunakan 2 metode tersebut didapatkan hasil klasifikasi untuk 5 kelas dengan nilai rata-rata 0.023 detik untuk maximum likelihood dan 0.031 untuk metode NDVI.

\section{KESIMPULAN}

Penelitian ini menunjukkan bahwa kinerja algoritme kemungkinan maksimum menghasilkan akurasi yang lebih baik $(95,81 \%)$ daripada hasil yang dihasilkan oleh NDVI $(92,85 \%)$ untuk proses klasifikasi di DAS Rindu Hati. Pengujian dilakukan ke dalam 100 titik data acak dari hasil klasifikasi dalam kegiatan pemeriksaan lapangan. Kemungkinan maksimum juga menunjukkan pemrosesan waktu yang lebih baik untuk klasifikasi 5 kelas pada nilai rata-rata 0,023 detik daripada algoritme NDVI yang menunjukkan nilai rata-rata 0,031 detik. Sehingga dapat di simpulkan bahwa kinerja algoritme maximum likelihood pada pemrosesan remote sensing lebih direkomendasikan dibandingkan dengan metode NDVI. 


\section{REFERENSI}

[1] Y.-B. Y.-P. Y.-B. Y.-P. Lin, Y.-B. Y.-P. Y.-B. Y.-P. Lin Y.-T. Wang, and N.-M. Hong, "Monitoring and Predicting Land-use Changes and the Hydrology of the Urbanized Paochiao Watershed in Taiwan Using Remote Sensing Data, Urban Growth Models and a Hydrological Model," Sensors, vol. 8, no. 2, pp. 658-680, 2008.

[2] C. J. Reeling and B. M. Gramig, "A novel framework for analysis of cross-media environmental effects from agricultural conservation practices," Agric. Ecosyst. Environ., vol. 146, no. 1, pp. 44-51, 2012.

[3] Ministry of Forestry of the Republic of Indonesia, "Consolidation Report Reducing Emissions From Deforestation And Forest Degradation In Indonesia," 2008.

[4] Wiratno, "Resort Based Management: Learning Process from East Nusa Tenggara." The Ministry of Forestry Indonesia, Indonesia, p. 48, 2013.

[5] L. Z. Mase, "Slope Stability and Erosion-Sedimentation Analyses Along Sub-watershed of Muara Bangkahulu River in Bengkulu City, Indonesia," E3S Web Conf., vol. 148, 2020.

[6] D. Armenteras, G. Rudas, N. Rodriguez, S. Sua, and M. Romero, "Patterns and causes of deforestation in the Colombian Amazon," Ecol. Indic., vol. 6, no. 2, pp. 353 368, 2006.

[7] T. Santika et al., "Community forest management in Indonesia: Avoided deforestation in the context of anthropogenic and climate complexities," Glob. Environ. Chang., vol. 46, no. December 2016, pp. 60-71, 2017.

[8] A. M. Arymurthy and E. P. Purwandari, "ANALISIS TOPOLOGI DAN POPULASI PENDUDUK PEMUKIMAN MISKIN MENGGUNAKAN TEKNOLOGI REMOTE SENSING," J. Sist. Inf., vol. 6, no. 1 , pp. 20-31, 2012.

[9] W. Wu, "Derivation of tree canopy cover by multiscale remote sensing approach," Work. Geospatial Data Infrastruct. from data Acquis. Updat. to smarter Serv., no. Cc, pp. 142-149, 2002.
[10] K. Prabhakara, W. D. Hively, and G. W. McCarty, "Evaluating the relationship between biomass, percent groundcover and remote sensing indices across six winter cover crop fields in Maryland, United States," Int. J. Appl. Earth Obs. Geoinf., vol. 39, pp. 88-102, 2015.

[11]S. N. Wood, "Fast stable restricted maximum likelihood and marginal likelihood estimation of semiparametric generalized linear models," J. R. Stat. Soc. Ser. B Stat. Methodol., vol. 73, no. 1, pp. 3-36, 2011.

[12]S. Boroushaki and J. Malczewski, "Measuring consensus for collaborative decision-making: A GIS-based approach," Comput. Environ. Urban Syst., vol. 34, no. 4, pp. 322-332, 2010.

[13]M. Bottero, E. Comino, M. Duriavig, V. Ferretti, and S. Pomarico, "The application of a Multicriteria Spatial Decision Support System (MCSDSS) for the assessment of biodiversity conservation in the Province of Varese (Italy)," Land use policy, vol. 30, no. 1, pp. 730-738, 2013.

[14]L. Gandharum, C. Chen, P. Teknologi, I. Sumberdaya, and A. Ptisda, "Pemanfaatan Informasi Tekstur untuk Klasifikasi Tanaman Sawit Menggunakan Citra FORMOSAT-2," 2008.

[15]C. Maione, B. L. Batista, A. D. Campiglia, F. Barbosa, and R. M. Barbosa, "Classification of geographic origin of rice by data mining and inductively coupled plasma mass spectrometry," Comput. Electron. Agric., vol. 121, pp. 101-107, 2016.

[16]D. H. Hoekman, M. A. Vissers, and N. Wielaard, "PALSAR Wide-Area Mapping of Borneo: Methodology and Map Validation," IEEE J. Sel. Top. Appl. Earth Obs. Remote Sens., vol. 3, no. 4, pp. 605-617, 2010.

[17] S. Aksoy and H. G. Akcay, "Multi-resolution segmentation and shape analysis for remote sensing image classification," Recent Adv. Sp. Technol. 2005. RAST 2005. Proc. 2nd Int. Conf., pp. 599-604, 2005. 